\title{
COMPREENDENDO A AGRESSIVIDADE INFANTIL A PARTIR DE PESQUISA REALIZADA EM BRINQUEDOTECA ESCOLAR: UMA ABORDAGEM PSICANALÍTICA
}

\author{
Andreia Cristiane Silva Wiezzel ${ }^{1}$, Fabio Camargo Bandeira Villela ${ }^{1}$, Tagiane Maria da Rocha Luz $^{2}$ \\ ${ }^{1}$ Universidade Estadual Paulista - UNES, Departamento de Educação, Presidente Prudente, SP. ${ }^{2}$ Universidade Estadual \\ do Paraná - UNESPAR, Centro de Ciências Humanas e da Educação, Paranavaí, PR. E-mail: andreia@fct.unesp.br
}

\section{RESUMO}

Este artigo envolve investigação acerca do impacto das condutas agressivas do brincar de uma criança da educação infantil, buscando identificar os fatores emocionais que influenciaram sua agressividade. O projeto é amparado em autores da psicanálise, particularmente Aberastury, Bowlby e Winnicott. É desenvolvido por meio de observações em sala de aula, entrevistas com pai e professora e atividades lúdicas com a criança participante, como instrumentos de coleta de dados. Por meio das observações e intervenção lúdica, puderam-se verificar evoluções no desenvolvimento da capacidade de brincar da criança. Foi possível à criança expressar e trabalhar com alguns sentimentos que a incomodavam e lhe causavam tristeza e insegurança, tendo alguém para compreender e sobreviver às suas atitudes hostis. Dentre os fatores que interferiram na agressividade excessiva dessa criança, podem ser citadas a história de vida, características do desenvolvimento emocional e influência ambiental, sobretudo nos seus primeiros anos de vida.

Palavras-Chave: agressividade, educação infantil, brincar, Winnicott.

\section{UNDERSTANDING INFANTILE AGGRESSION FROM RESEARCH CARRIED OUT IN A PLAYSCHOOL: A PSYCHOANALYTICAL APPROACH}

\begin{abstract}
This article involves investigation concerning the impact of aggressive behavior in play of a child in infant education, looking to identify the emotional factors influencing his aggression. The project is rooted in the work of psychoanalytical authors, in particular Aberastury, Bowlby and Winnicott. It has been developed through classroom observation, parent-teacher interviews, and play activities involving the child as means of data collection. Through observation and the play intervention, it was possible to point to evolutions in the development of the child's ability to play. Having someone to understand and survive his hostile attitude enabled the child to express and work through some of the feelings that caused him distress and insecurity. Life history, characteristics of emotional development and environmental influence, especially in the first years of life, can be cited among the factors contributing to this child's excessive aggression.
\end{abstract}

Keywords: aggression, infant education, play, Winnicott. 


\section{INTRODUÇÃO}

Na educação infantil, oscilações de humor são frequentes, em decorrência da capacidade da criança de conhecer e controlar os próprios impulsos e sentimentos estar nos primeiros tempos do processo de amadurecimento individual. No entanto, observamos crianças em que a agressividade aparece como gesto predominante em sala de aula. Autores como BOLWBY (1989) e WINNICOTT $(2008 ; 1990 ; 1975 ; 2005)$ teorizam que, quando isso ocorre, estamos diante de crianças que vivenciaram algum tipo de perda, falhas excessivas ou intrusão ambiental.

Diante do exposto, pretende-se discutir o caso de uma criança predominantemente agressiva com colegas da escola e apresentar uma intervenção que possibilitou evoluções positivas em seu desenvolvimento.

O objetivo desse estudo foi compreender a agressividade infantil a partir de pesquisa realizada em brinquedoteca escolar especialmente a partir de uma abordagem psicanalítica. Subsidiariamente, pensou-se em formas de se lidar com a agressividade infantil no contexto da escola e da sala de aula.

\section{METODOLOGIA}

A presente pesquisa desenvolveu-se como estudo de caso de um garoto de 4 anos de idade - Lucas (nome fictício) - de uma escola de Educação Infantil do interior de São Paulo - SP. O projeto (Processo 045860/2014) teve como instrumentos de coleta de dados observações em sala de aula, entrevistas abertas com o pai e a professora e, especialmente, o desenvolvimento de atividades lúdicas com a criança, na brinquedoteca da escola. As atividades lúdicas ocorreram semanalmente e tinham a duração de 50 minutos. Lucas teve liberdade de escolher os brinquedos e brincar espontaneamente com eles, assim como brincar ou não com a pesquisadora, que observava a sua atitude em busca de dados relevantes aos objetivos do trabalho.

\section{RESULTADOS}

Lucas nasceu prematuramente, permanecendo por quinze dias em incubadora. Após sair do hospital, ficou aos cuidados da avó por outros quinze dias e, nos seis primeiros meses de nascimento (já em um bercário infantil), necessitou de muitos cuidados, pois teve refluxo.

O ambiente no qual vivia envolvia desentendimentos e vícios. Os pais trabalhavam muito e, até mesmo durante as férias escolares, o garoto era mantido na instituição. $O$ pai destacou que os atos agressivos do garoto tiveram início em 2014, quando mudou de escola. Relatou, ainda, que o garoto era agitado, ansioso e nervoso, apresentando dificuldades com o sono.

O pai de Lucas afirmou considerar-se nervoso e gostar muito de festas. A mãe já era mais reservada e ficava incomodada quando o marido saía. No final de 2014 , começou a consumir bebidas alcoólicas, tendo o garoto encontrado-a caída ao chão, com copos quebrados próximos a seu corpo. Nessa ocasião, o pai solicitou uma ambulância e ela foi levada ao hospital. Com a separação dos pais, Lucas foi morar na casa dos avós, juntamente com a mãe. O pai o visitava nos finais de semana.

Em relação à escola, a professora disse que Lucas era calado, resistente, agitado, nervoso e desobediente. Quando era repreendido, fazia expressão de deboche, sorria, fazia caretas. Como agredia fisicamente as outras crianças, essas evitavam contato com ele.

O primeiro encontro lúdico de Lucas foi marcado por uma brincadeira muito expressiva: havia um carro e um caçador (representado por um boneco), ambos trocavam algumas palavras e, em determinado momento, o caçador era atropelado pelo carro. O caçador se escondia e apareciam outros carros, que batiam "de frente".

Nos encontros seguintes, foram utilizados serra, martelos, carros, barco e estetoscópio. 0 martelo foi utilizado para consertar o barco por meio de batidas e, sobre o barco, o garoto colocava um boneco, que usava o estetoscópio como uma arma. 
Além dessa brincadeira, brincou na piscina de bolinhas - momento em que pode se aproximar afetivamente da pesquisadora - e voltou a pegar os carrinhos e brincar com eles, só que, nesse momento, em uma estrada. Repetiu, por algumas vezes, que a estrada estava quebrada e que iria consertá-la com um martelo. Martelava a estrada por várias vezes, para que os carros pudessem passar. Martelava os carrinhos e bonecos, em uma tentativa de também consertá-los. Cada vez era um carrinho que ganhava a corrida e ele tentava alinhar os três carrinhos, para que todos permanecessem na mesma posição na estrada. Ao final, colocou um carrinho no bolso, sem pedir autorização da pesquisadora.

As brincadeiras mantiveram-se no mesmo formato, apenas mudavam os objetos: arma de brinquedo, serrote, chave de fenda. Tentava repetidamente consertar os objetos e bonecos, dizendo que ora estava feliz, ora triste. Alternava essa brincadeira com as corridas.

Lucas ficou doente e faltou à escola por muitos dias. Quando retornou, pegou um quebracabeça e ficou por longo tempo tentando montá-lo. Como não conseguiu, pediu ajuda à pesquisadora. Enquanto montavam, começou a relatar sobre o momento em que encontrou a mãe caída quando retornou da escola. Disse que havia vários copos quebrados e que seu pai jogou água nela e depois chamou o médico. O garoto pareceu estar impressionado com a cena e angustiado, pois pensara que sua mãe havia morrido. Este temor repetia-se tanto que, todos os dias em que saía para escola, pedia à mãe para não dormir no chão.

Com o passar dos encontros lúdicos, o garoto conseguiu internalizar um ambiente bom e formular uma questão a respeito de sua condição psíquica - um quebra cabeça que não sabia como montar. Ao pedir ajuda a alguém para conseguir montá-lo, observa-se a fruição do sentimento de confiança, fundamental ao desenvolvimento emocional (WINNICOTT, 1975).

Lucas demonstrava, em alguns momentos, que a própria estrada se quebrava e tentava, repetidamente, consertá-la. Compulsivamente buscava reconstruir, consertar objetos e consertar as "pessoas" para que pudessem percorrer a estrada. Para ele, não estava claro se a dificuldade residia nas pessoas, na estrada ou nos dois, então testava soluções em todos os âmbitos. Crê-se que seus conflitos estavam em torno de duas questões: a reconstrução da relação entre a família e a necessidade de prosseguir em seu desenvolvimento.

Na semana seguinte, relatou um sonho, no qual a mãe corria perigo. Disse que havia muitos monstros - entre eles o caçador - e o Homem-Aranha tentava salvá-la. Por fim, brincou de mágico - fazendo os brinquedos aparecerem e desaparecerem - e com os bonecos, brincadeira também muito expressiva: havia dois bonecos, os quais ele apelidou de Gigante e Pequeno. Ele ficou com o Gigante e a pesquisadora com o boneco pequeno. O Gigante saía atrás do boneco pequeno em uma perseguição pela floresta (ele correu atrás da pesquisadora pela brinquedoteca). O boneco pequeno voltava para sua caverna e esperava o Gigante dormir. Após o Gigante adormecer, o Pequeno se aproximava e cortava-o com uma faca, voltando à caverna. O Gigante acordou e foi ao médico, tomou remédio e ficou bem, porém, quando foi se alimentar, morreu. Repetiu a brincadeira.

No último dia de encontro, brincando de médico, pegou o "telefone" e fez uma ligação, pedindo ajuda ao médico. "Medicou" a pesquisadora, colocando um remédio em sua boca e fez um curativo, que colocou em seu próprio braço. De uma realidade em que o estetoscópio foi identificado a uma arma, a criança ligou para um médico e "medicou" a pesquisadora e a si próprio.

\section{DISCUSSÃO}

Para Aberastury (1992), o brincar tem como funções expressar o mundo interno da criança, possibilitar o domínio de angústias, auxiliar a criança a adquirir experiências, desenvolver a socialização e também constitui forma de diversão. O brincar tem ainda um caráter terapêutico, que ajuda a criança a se desenvolver e a aprender. 
Não é fácil trabalhar com crianças com dificuldades de estabelecer vínculos tranquilos, já que a situação envolve, predominantemente, o desenvolvimento emocional. Por meio do lúdico, conforme Winnicott (2005), é possível à criança reformular seus sentimentos internos e externos, de forma que as condutas agressivas sejam minimizadas.

O relato sobre Lucas indica que o garoto externalizou ódio durante o brincar. Essa externalização ocorreu porque sentiu que a pesquisadora sobreviveria afetivamente às fantasias de morte, à agressão. Nesse sentido, o garoto pode brincar com suas fantasias de morte, carregadas de ódio, sem sentir a ameaça de que alguém realmente morresse e que houvesse um retorno retaliativo do meio. Ao mesmo tempo, a agressividade pode ser escoada, livrando o mundo interno do sentimento de ódio, que tende a destruir os pensamentos objetivos e os vínculos (WINNICOTT, 1982).

Assim, a criança estava conseguindo identificar-se melhor com o pai bom que socorreu a mãe e menos com o pai mau que se ausentava e fazia a mãe sofrer. Foi abrandada a presença de figuras persecutórias durante o brincar, acredita-se que em decorrência de a criança ter elaborado o "Gigante" como, predominantemente, o pai bom.

As raízes da agressividade observadas em Lucas possuem componentes que podem ser esclarecidos pela teoria psicanalítica de Donald W. Winnicott. Após o nascimento, o bebê precisa da mãe ou de um cuidador que se adapte às suas necessidades, principalmente quando solicitadas. "A vivência de uma relação calorosa, íntima e contínua com a mãe ou mãe substituta permanente, ou seja, uma pessoa que desempenha, regular e constantemente, o papel da mãe, mostra-se essencial à saúde mental do bebê" (BOLWBY, 1989, p. 139). É esse cenário que não encontramos nem de longe na história de Lucas: desde o nascimento apresenta uma história de distanciamento e separação de sua mãe e de seu pai em relação a ele.

Segundo Winnicott (1982), a mãe, ao acolher seu filho, depara-se invariavelmente com situações de difícil manejo, como a mordida no seio, algo que causa dor física e psíquica e que é decorrente das primeiras manifestações de agressividade. O bebê pode morder o seio por diversos motivos, como o de sentimento de frustração ou estado de excitação. Para Winnicott (2000) o bebê é ruthlessness, suas atitudes impiedosas provêm do componente agressivo que, lado a lado do componente libidinal, manifesta-se no âmago do recém-nascido, impulsionando-o a experienciar o viver.

Durante os primeiros meses de vida, o bebê tende, pouco a pouco, a reconhecer o que é "eu" e o que é "não eu". Devido à sua incapacidade inicial de estabelecer tal distinção, a agressividade é não intencional e, juntamente com gestos espontâneos, manifestados desde o útero, dá início ao processo de integração (idem, 1990). O ambiente facilitador provê o necessário para que o bebê comece a distinguir o "eu" e o "não eu" e, assim, alcance o estado de integração.

A integração do "eu", ou integração egóica, significa que, de um estado de pré-fusão entre o componente agressivo e o libidinal próprio da condição de não integração, realizou-se a fusão entre os componentes impulsivos (CELERI e OUTEIRAL, 2005). O ambiente em que o bebê estiver se desenvolvendo será fundamental para que passe do estado ruthlessnes para o estado de concern - ou de concernimento - com os efeitos da agressividade no outro. A sobrevivência da mãe suficientemente boa ao estádio de ruthlessness, ou seja, da mãe que não retalia os gestos do bebê, será imprescindível para que este alcance o estado de concern e se torne preocupado com seu objeto mãe e com as consequências de sua voracidade - ou agressividade de um modo geral a ela dirigida.

Segundo Winnicott (1983), a sobrevivência refere-se à continuidade do cuidado ao bebê em seus diferentes estados psíquicos e físicos. De modo a sistematizar esse cuidado, o autor enfatiza a sobrevivência da mãe ambiente e a sobrevivência da mãe objeto no cotidiano. A mãe ambiente refere-se ao cuidado com os estímulos ao corpo do bebê e a mãe objeto refere-se àquela que elimina a tensão psíquica proveniente das necessidades físicas, através da 
amamentação. A sobrevivência da mãe ambiente e da mãe objeto instala o ambiente facilitador aos processos de desenvolvimento emocional. No caso de Lucas, a mãe não sobrevive - no sentido winnicottiano - aos seus ataques e dificuldades, o que dificulta seu desenvolvimento emocional e alimenta a fantasia de dano e morte que pode provocar às pessoas que mais ama.

Aproximadamente aos seis meses, tendo experienciado estados integrados e retornos a estados de não integração, o bebê torna-se capaz de perceber características do mundo real e, consequentemente, desenvolve-se o sentimento de culpa, que é alcançado juntamente com o estádio de concern. No estádio de concernimento, a agressividade tende a ser diminuída em decorrência de o bebê ter um sentimento de pesar em relação aos efeitos dos seus gestos no mundo interno da mãe. Teme a perda do objeto bom e sente também ansiedade, em decorrência de estes temores despertarem a intuição a respeito da própria fragilidade.

A força provinda do componente agressivo tende a ser parcialmente convertida em manifestações que sejam reparadoras e demonstrem gratidão do bebê em relação à mãe. A criança não contida entende que pode acabar com o mundo por meio de seus impulsos destrutivos. Assim, pode passar a temer esse poder de destruição e não confiar nesse mesmo mundo, cujas pessoas podem persegui-la e retaliá-la a qualquer momento.

Acredita-se que a criança que desenvolveu o sentimento de concern consegue viver bem a experiência escolar, diferentemente da criança agressiva, que não conseguiu alcançar um estado de integração em bases firmes.

Quando a agressividade não é contida no ambiente familiar, a criança vai buscar na escola a completude da sustentação emocional proporcionada pelo ambiente, tentando obter um espaço no qual se sinta segura e auxiliada em seus momentos de cólera. Quando essa contenção é encontrada em casa, a criança vai à escola mais em busca do desenvolvimento intelectual e da aprendizagem (Winnicott, 2005).

Lucas pode, por meio dos encontros lúdicos da brinquedoteca escolar, lidar com seus temores de separação em relação à mãe e ao pai, assim como seus temores de castração, abandono e morte. Sua capacidade para o brincar estava preservada em um ambiente acolhedor e continente em relação a seus temores e fantasias. Consegue, ao longo dos encontros lúdicos, elaborar criativamente o sentimento de que havia a possibilidade de que algo pudesse ser consertado. Percebe-se, nesse relato, o efeito empático e terapêutico da Brinquedoteca escolar, verificando-se a possibilidade de a instituição escolar ter condições de oferecer um acolhimento emocional que, muitas vezes, a instituição familiar não tem condições de prover (VILLELA e ARCHANGELO, 2013).

\section{CONCLUSÃO}

Inspirando-se na teoria winnicottiana sobre a mãe suficientemente boa, buscou-se delinear atitudes para o atendimento lúdico em uma brinquedoteca escolar que fossem benéficas ao desenvolvimento de uma criança na escola. Trabalhou-se com o conceito de sobrevivência da mãe suficientemente boa diante do bebê em estado de ruthlessness e discutiu-se a ocorrência da capacidade emocional de quem brincasse com a criança de escutar pacientemente, criar vínculo de confiança e sobreviver à destrutividade presente no brincar, sem estranhar ou retaliar os gestos da criança. $\mathrm{O}$ acolhimento modificou a dinâmica do brincar, antes caracterizado por ideias e afetos persecutórios, passando a ser composto de sentimentos de acolhimento, preocupação e reparação.

A pesquisa mostrou que a conduta agressiva se trata de um processo que envolve diversos fatores de ordem individual e social, não sendo possível identificar um único fator como responsável por sua ocorrência. Diante disso, percebe-se a importância de a escola ter consciência desses fatores, pois muitos deles podem ser evitados ou evoluírem positivamente, por meio de um manejo ambiental que forneça condições favoráveis ao desenvolvimento emocional. 
O adequado cuidado com crianças que se mostram agressivas não deve ficar inscrito nos estritos limites de uma eventual brinquedoteca escolar. No entanto, a brinquedoteca escolar com foco no desenvolvimento emocional não deixa de ser um local muito especial para crianças que apresentem consideráveis dificuldades emocionais, como também serve para a compreensão da dinâmica da agressividade em criança pequenas. Para além disso, possibilita reflexões a professores e equipe técnica sobre as possibilidades de se lidar com as dificuldades emocionais apresentadas pelo aluno, sobretudo no âmbito da sala de aula, extrapolando-se, assim, o restrito, fascinante e mágico local de uma brinquedoteca escolar.

\section{REFERÊNCIAS}

ABERASTURY, A . A criança e seus jogos. 2 ed. Porto Alegre: Artmed, 1992.

BOWLBY, J. Uma base segura: aplicações, clínica da teoria do apego. Porto Alegre: Artes Médicas, 1989.

CELERI, E. H. R. V; OUTEIRAL, J. Existiria o equivalente ao instinto de morte no pensamento de Winnicott - Algumas reflexões sobre ser, não ser e solidão essencial? Winnicott: seminários brasileiros. Rio de Janeiro: Revinter, 2005. p. $434-440$.

VILLELA, F. C. B; ARCHANGELO, A. Fundamentos da escola significativa. 1 ed. São Paulo: Loyola, 2013. 140p.

WINNICOTT, D. W. A criança e o seu mundo. 6 ed. Rio de Janeiro: LTC, 2008. . Natureza Humana. Rio de Janeiro: Imago, 1990.

. O brincar e a realidade. Rio de Janeiro: Imago, 1975.

Privação e delinquência. 4 ed. São Paulo: Martins Fontes, 2005. 